\title{
A LITERATURA É UMA GEOGRAFIA?
}

\section{IS THE LITERATURE A GEOGRAPHY?}

\section{EST LITTÉRATURE UNE GÉOGRAPHIE?}

\author{
Ida Alves ${ }^{1}$ \\ Universidade Federal Fluminense, Niterói, Brasil/CNPq
}

Resumo: Desenvolve-se reflexão sobre a relação literatura e paisagem, a partir de fundamentação teórico-crítica que aborda a paisagem como construção cultural capaz de expressar de maneira questionadora a relação entre sujeito, mundo e palavra. A presença da paisagem em alguma produção poética de língua portuguesa pós-70 do século XX e a configuração de uma geografia lírica urbana produzida por subjetividades em tensão.

Palavras-chave: poesia contemporânea; paisagem; geografia literária.

Abstract: It is developed a reflection about the relation between literature and landscape, from a theoric-critic fundamentation that deals with the landscape as cultural building able to express in a questioning manner the relation between subject, world and word. The presence of landscape in some poetic production of the Portuguese language after the 1970s and the configuration of a urban lyrical geography from stressed subjectivites.

Keywords: contemporary poetry; landscape; literary geography.

Resumé: Il s'agit de réflechir sur le rapport entre littérature et paysage à partir d'une formulation teorique-critique qui discute le paysage comme une élaboration culturelle qui peut questioner le rapport entre le sujet, le monde et le mot. On examine brièvement quelque production poétique de la langue portugaise post-70 du XX eme. siécle sous la perspective des études du paysage et la configuration d'une geographie lyrique urbane produisée par des subjectivités en tension.

Mots-clé: poésie contemporaine; paysage; géographie littéraire.

\section{INTRODUÇÃO}

O título interrogativo deste artigo é uma forma de pensar que relações podemos traçar entre Literatura e Geografia. Se, do ponto de vista das classificações acadêmicas e áreas de conhecimento dos órgãos de fomento, trata-se de dois domínios distintos, na perspectiva dos escritores, há trajetos de reflexão comuns os quais servem de pontes

\footnotetext{
${ }^{1}$ Professora titular de Literatura Portuguesa do Instituto de Letras da Universidade Federal Fluminense (UFF) e pesquisadora 2 do CNPq. E-mail: idafalves@gmail.com
} 
entre essas grafias do mundo. Não é propriamente original falar disso, mas, entre nós, esse ângulo de apreciação não tem merecido uma atenção mais detida, pelo menos na área dos estudos literários. Por isso, este trabalho parte da interrogação para problematizar a produtividade desse encontro interdisciplinar. Ainda que seja uma reflexão breve, desejo demonstrar as possibilidades de diálogo, e especialmente chamar a atenção para a necessidade de pensar a poesia, essa escrita também sempre um pouco à margem, como um campo apreciável de uma geo-grafia, na medida em que constitui um pensamento inquieto sobre nosso estar no mundo e na linguagem. Nesse contexto, o operador de sentido é a paisagem, a partir do que discute Michel Collot (Professor de Literatura Francesa da Université Sorbonne Nouvelle - Paris 3), em suas diversas obras sobre paisagem no âmbito da teoria da lírica moderna e contemporânea. Farei referência a alguma poesia contemporânea de língua portuguesa para tentar demonstrar formas de perceber o mundo a partir da presença/ausência da natureza.

\section{PAISAGEM E LITERATURA}

Nas últimas décadas, a consciência sobre a importância do meio ambiente tem se desenvolvido de forma acentuada frente aos mais diversos problemas provocados pelas modificações que o homem imprime ao espaço circundante. As ações predatórias contra a natureza, a sua rarefação frente à expansão cada vez maior da malha urbana, tem fomentado uma discussão ampla sobre a questão paisagística. Renomados geógrafos, antropólogos e sociólogos, desde os anos 70, têm publicado trabalhos fundamentais na área, renovando o modo de considerar e compreender a paisagem e sua relação com a cultura. Em decorrência, o conceito de paisagem foi retomado, para além da geografia cultural, em diversas áreas de reflexão como a história da arte, semiologia, arquitetura, sociologia, psicologia, antropologia, história e filosofia, em diferentes níveis de análises morfológica, funcional e simbólica. Essas abordagens propõem, naturalmente, diferentes conceituações de paisagem, mas há um ponto comum na diversidade: a paisagem retorna com uma questão e um problema, é compreendida como um dado construído, envolvendo percepção, concepção e ação, vindo a constituir uma estrutura de sentidos, uma formulação cultural, como discutem, em obras já referenciais, Alain Corbin (1989), Augustin Berque (1994), Simon Schama (1995), Alain Roger (1997), 
entre outros pesquisadores de destaque. Todos esses trabalhos se entrecruzam na concepção de que compreender a paisagem é compreender a relação que o homem mantém com o mundo por meio da experiência do olhar e do domínio da palavra. Como afirmou Berque, a paisagem

ne réside ni seulement dans l'objet, ni seulement dans le sujet, mais dans l'interaction complexa de ces deux termes. Ce rapport, qui met em jeu diverses échelles de temps et d'espace, n'implique pas moins l'institution mentale de la réalite que la constitution matérielle des choses. Et c'est à la complexité même de ce croisement que s'attache l'étude paysagère. (BERQUE, 1994, p. 5).

Já Alain Roger buscou demonstrar como a paisagem resulta de um processo que ele denominou de "artialização", ou seja, "est un produit de l'art", construção da sensibilidade humana frente ao mundo (ROGER, 1997, p. 18).

Desde o desenvolvimento de minha pesquisa de doutorado em Letras, no final dos anos noventa, atentei para a relação forte existente entre a escrita poética e a configuração de paisagens. Naquele momento, a leitura das primeiras obras de Michel Collot, hoje um dos nomes mais referenciados nos estudos de paisagem no âmbito de Letras, foi a motivação necessária para aprofundar o entendimento dessa relação. Bem sabemos que o estudo do espaço é uma constante nos estudos narrativos e a própria literatura brasileira produziu obras emblemáticas em torno da experiência espacial como Vidas Secas, de Graciliano Ramos e Os Sertões, de Euclides da Cunha, apenas para citar dois títulos evidentes. Mas, somente quase uma década depois, pude realmente propor um estudo persistente sobre as configurações e desfigurações da paisagem no âmbito da poesia portuguesa, meu campo de reflexão, discutindo a percepção da paisagem como processo relacional entre obra e mundo, registro de lugares de habitação e construção cultural, social e estética, a partir de experiências contemporâneas de sujeitos individuais ou coletivos.

No desenvolvimento dessa pesquisa mais sistematizada, foi possível contatar outros investigadores brasileiros e estrangeiros, especialmente franceses e portugueses, preocupados com a paisagem e sua presença no texto literário, numa vontade também de constituir uma geografia literária. Esse encontro de interesses possibilitou a criação, entre nós, do Grupo de Pesquisa UFF/CNPq Estudos de Paisagem nas Literaturas de 
Língua Portuguesa $^{2}$ e a ampliação de uma rede de interesse sobre a questão paisagística em diferentes direções. Se, na área da geografia humana culturalista, os estudos paisagísticos têm presença forte, na área de letras, estudar paisagem parecia ser um retorno pouco original a um tema do passado, já que falar de paisagem foi um ponto nodal do Romantismo brasileiro em confronto com os tópicos comuns da natureza romântica europeia. Antonio Candido escritor, ensaísta, crítico e professor titular de teoria literária e literatura comparada da USP, demonstrou há muito como a paisagem foi um dispositivo fundamental para constituição da identidade nacional na literatura brasileira. A partir do Modernismo, o tema da paisagem recebeu, de forma geral, dois tratamentos: de um lado, houve certo afastamento da questão como reação a nacionalismos governamentais ufanistas ou identidades simplistas; de outro, a partir de um engajamento político forte, de orientação especialmente marxista, cresceu uma produção literária regionalista (sobretudo, Norte e Nordeste) aliando denúncia social, observação espacial e arte: muito se escreveu sobre a seca e a miséria decorrente do homem nordestino, sobre o ciclo da borracha e, depois, a exploração madeireira na floresta amazônica ou a destruição dos espaços indígenas etc. No contemporâneo, voltar a falar de paisagem parecia, portanto, um anacronismo ou um déjà-vu sem maior consequência. No entanto, a força dos estudos paisagísticos, hoje, é inegável e o diálogo entre geografia e literatura ou geografia e áreas como Filosofia, Estética, História e afins é inevitável.

O interesse atual do tema, na área de Letras, advém da certeza de que é preciso encontrar um lugar novo para compreender a relação entre o homem e o mundo, ainda mais se consideramos que estamos vivendo num tempo de um urbanismo veloz que vai, inexoravelmente, afastando a natureza do homem comum. As obras literárias do presente, como contemporâneas que são, não evitam de apresentar a questão urbana e, em decorrência, de refletir sobre as figurações ou desfigurações da natureza frente a experiências de sujeitos fortemente marcados por novas relações com o espaço e a visualidade.

Isso me conduz ao reencontro com Michel Collot e todo o seu trabalho desenvolvido em mais de trinta de anos de publicações e atividades de pesquisa e ao mapeamento de grupos de investigação brasileiros e estrangeiros para dialogar. Para

\footnotetext{
${ }^{2}$ http://www.gtestudosdepaisagem.uff.br.
} 
muitos talvez não seja de conhecimento, por exemplo, a existência de um Grupo da Universidade Nova de Lisboa que vem elaborando um Atlas das Paisagens Literárias de Portugal Continental ou do próprio Seminário Permanente, coordenado por Michel Collot, na Université Sorbonne Nouvelle - Paris 3, intitulado "Vers une géographie littérarie", no âmbito de Programme de Recherche "Écritures de la Modernité" ou do Grupo Paisagem e Património - Seminário Interdisciplinar de Investigação - CHAIA Centro de História da Arte e de Investigação Artística, na Universidade de Évora. Do lado brasileiro, os grupos dedicados aos estudos de paisagem são poucos e, de certa maneira, isolados. É com esses Grupos que nossa equipe vem dialogando, buscando realmente confirmar e divulgar a importância, hoje, de voltar à paisagem com uma perspectiva analítica e crítica contemporânea e instigante.

Ora, frente à nossa realidade cotidiana, onde está a paisagem? Se aceitamos que ela é uma construção cultural a partir do olhar que o homem lança à natureza, não é a cidade uma paisagem dominante, produto da ação humana exatamente sobre a natureza? Se é verdade que a literatura continua a nos dar muitos exemplos de escrita sobre elementos da natureza, a presença do mar, da floresta, do deserto, por exemplo, em narrativas ou poemas, é também pertinente dizer que o tecido urbano é uma grafia que o literário examina e expõe. Antropólogos e sociólogos como Paul Virilio e Zingmunt Bauman vem publicando inúmeras obras sobre a relação intima entre o homem e seu espaço de habitação, cada vez mais urbano, e as novas relações que a tecnologia vem provocando na ocupação desse espaço. Virilio, com sua dromologia, evidencia a velocidade como um dos vetores mais importantes na compreensão de novas relações entre os sujeitos e o espaço à volta, assim como o excesso de visualidade e virtualidade que, inevitavelmente, são as marcas características de nosso presente de megalópoles e metrópoles. Em decorrência dessa realidade perceptiva transformada, estabelecem-se novos problemas e questões a resolver. A literatura, portanto, não pode ser indiferente a isso e não é, já que o texto literário é sempre do seu presente e é sempre uma grafia do mundo que se pisa concretamente, ainda que os caminhos sejam ficcionais.

\section{POESIA E PAISAGEM}

No meu percurso de pesquisa sobre a linguagem e os percursos da poesia 
contemporânea, no espaço da língua portuguesa, busco não apenas a compreensão de uma determinada produção poética de um autor, mas o delineamento de uma lírica de caráter urbano a refletir o nosso tempo. O importante, portanto, é o diálogo que essas obras poderão permitir expondo questões similares próprias ao nosso presente e ao seu universo cultural. Também busco comprovar uma hipótese: que essa produção se constrói, dominantemente, com uma escrita elegíaca, ou seja, transforma em linguagem lírica sua relação lutuosa com a cidade, já que se afirmam subjetividades em falha e descontentes com um espaço que consideram arruinado, desfigurado e provisório. As experiências do urbano em diversas poéticas denotam, pois, uma percepção pessimista de mundo, tornando visível uma ausência da natureza, com os sujeitos a experimentarem os não-lugares (AUGÉ, 2004) cada vez mais presentes na vida citadina.

Ainda que cada poeta desenvolva uma linha de apreensão do mundo, observamos, por exemplo, na poesia publicada desde os anos 70 um olhar mais acentuadamente urbano e uma atenção mais evidente sobre subjetividades que se figuram nas experiências da errância, da mobilidade e da ausência. A paisagem se estabelece como um problema com que o poeta se defronta e para o qual leva o leitor atento.

Nessas poéticas, a geografia é o entrecruzar de ruas ou estradas ou ir em busca de cidades que se vão mostrando também lugares sem memória e sem resistência à massificação cultural que parece atingir todos os espaços da terra hoje. Gosto sempre de citar uma passagem do estudo da geógrafa Ana Fani Carlos (2001) sobre a vivência do espaço urbano na metrópole de São Paulo, no qual afirma que o estranhamento e o desencontro são as consequências imediatas da experiência de um espaço radicalmente transformado frente a um tempo vivenciado na velocidade e no efêmero.

O ponto de partida de nossa pesquisa é o desencontro entre o tempo de transformação do espaço da metrópole - visto a partir das mudanças no plano da morfologia - e o tempo da vida de um indivíduo. [...] Diante de uma metróple em que a morfologia urbana muda e se transforma de modo muito rápido, os referenciais dos habitantes, produzidos como condição e produto da prática espacial modificam-se em numa outra velocidade, produzindo a sensação do desconhecido e do não identificado. (CARLOS, 2001, p. 328-329).

Esses dois conceitos que a pesquisadora destaca são produtivos para pensar 
como as subjetividades contemporâneas configuram a paisagem de hoje. Essas experiências de desencontro e de estranhamento estão significativamente presentes em obras poéticas em que podemos encontrar de forma evidenciada esse mal-estar existencial do sujeito lírico. Que experiência geográfica há para se escrever agora? Sem locus amoenus, sem Áticas, sem Novos Mundos, resta dizer a nossa vivência em espaços limitados e controlados e nossa epopéia particular é percorrer ruas com seus sinais, habitar em prédios, penetrar em cafés, shoppings, supermercados, perder-se em não-lugares como aeroportos, estações de trem, de metrô, sentido um momentâneo alívio ao pisar em jardisn públicos e artificiais. Essa poesia tão atenta ao cotidiano, acusada muitas vezes de superficial e descuidada na linguagem e na imagética, revela, com ironia e desilusão, novas geografias da emoção, do conformismo diário à amargura insolúvel.

Para o poeta carioca, por exemplo, a natureza é uma realidade muito presente no tecido urbano, muito constitutiva do seu modo de ser e viver: a praia principalmente, os morros que estão em todos os cantos da cidade, a floresta em perímetro urbano, o contorno da baia da Guanabara, o contraste de cores entre mar, vegetação e céu, enfim, a natureza, ainda que confrontada com o crescimento urbano (com média ou grande desordem urbana, em muitos casos), é tão presente que o olhar cotidiano acaba se tornando indiferente a ela. Para o poeta paulistano, talvez a materialidade dos altos prédios, a concentração de construções, a visualidade urbana sejam mais onipresentes. O elemento natural mais visível é o Rio Tietê ${ }^{3}$, que a atravessa, poluído pelo parque industrial e causador de inundações que, por vezes, param a metrópole. Como sabemos todos, São Paulo e Rio são complexos urbanos enormes, com populações em torno de 10 milhões a primeira, e 6 milhões a segunda ${ }^{4}$. A partir dos anos 80 , a violência foi se acelerando no Brasil em diversos níveis, situação provocada pela falta de políticas governamentais efetivas frente às injustiças e afrontamentos sociais, pelo desrespeito ao outro e pelo domínio do narcotráfico no espaço citadino (nas favelas do Rio e nas periferias de São Paulo, mas também presente em muitas outras cidades de porte médio e grande), o que gerou uma experiência urbana muito traumatizante. Isso refletiu-se, de

\footnotetext{
${ }^{3} \mathrm{O}$ termo "tietê" é originário da língua tupi e significa "água verdadeira", através da junção dos termos ty ("água") e eté ("verdadeiro"). Extensão de $1.010 \mathrm{~km}$.

${ }^{4}$ Compare-se com as três outras mais populosas cidades do Brasil: Salvador, Brasília e Belo Horizonte, cujas populações ficam em torno de 2,5 milhões.
} 
maneira geral, na produção literária brasileira contemporânea. Assim, por exemplo, os poetas de São Paulo expressam muitas vezes que a paisagem que lhes resta é a da metrópole de concreto, vidro e asfalto onde não há mais espaço para qualquer humanismo; os poetas do Rio contrastam a beleza da paisagem com a violência absurda que pode explodir a qualquer momento.

\section{SÍTIO}

O morro está pegando fogo.

$\mathrm{O}$ ar incômodo, grosso, faz do menor movimento um esforço, como andar sob outra atmosfera, entre panos úmidos, mudos, num caldo sujo de claras em neve.

Os carros, no viaduto, engatam sua centopeia: olhos acesos, suor de diesel, ruído motor, desespero surdo. O sol devia estar se pondo, agora _ mas como confirmar sua trajetória debaixo desta cúpula de pó, este céu invertido?

Olhar o mar não traz nenhum consolo (se ele é um cachorro imenso, trêmulo, vomitando uma espuma de bile, e vem acabar de morrer na nossa porta).

Uma penugem antagonista deitou nas folhas dos crisântemos e vai escurecendo, dia a dia, os olhos das margaridas, o coração das rosas.

De madrugada, muda na caixa refrigerada, a carga de agulhas cai queimando tímpanos, pálpebras:

O menino brincando na varanda. Dizem que ele não percebeu.

De que outro modo poderia ainda ter virado o rosto: "Pai!

acho que um bicho me mordeu!" assim que a bala varou sua cabeça?

manobra (2005).

ROQUETTE-PINTO, Cláudia. Margem de 
Mas, para uma percepção precisa em termos nacionais, teríamos que verificar como o texto poético se diferencia pelas diversas regiões e espaços brasileiros, como a paisagem é dispositivo de sentido em experiências tão diferentes de Brasil. Seria necessário confrontar imaginários e realidade do interior e do litoral, das grandes e pequenas cidades. Enfim, um trabalho monstruoso, sistemático, contínuo capaz de fornecer dados concretos para uma Geografia Literária Brasileira que está, sob novos parâmetros, por fazer.

Já na literatura portuguesa, duas construções imagéticas dominaram por longo tempo: de um lado, o espaço do mar, como desejo de horizonte, experiência de alteridade e poder; de outro, os limites da aldeia, como necessidade de enraizamento para um povo sempre em trânsito (nas navegações e nas emigrações do século XIX e $\mathrm{XX)}$. Entretanto, ao longo do século passado e sobretudo em seus últimos decênios, esses dois espaços imagéticos foram deslocados radicalmente pela necessidade de expressar a experiência urbana e suas novas práticas espaciais. Face a esse panorama, a ausência de paisagens naturais ou a certeza de sua degradação tornaram-se pontos constantes de observação na poesia mais recente. Nessa escrita, vê-se o domínio cada vez mais forte dos espaços fechados onde se abrigam sujeitos em busca de um campo de observação do mundo: os cafés, os bares, os quartos de pensão ou de hotéis, os automóveis, os trens, constatando a indiferença, o desencontro e o despaisamento.

Devemos lembrar que, em Portugal, país de tradição agrária, viu-se em rápida transformação a partir da abertura, em todos os níveis, provocada pela Revolução dos Cravos, em 1974. A partir daí não só se instituiu uma corrida social para recuperar o tempo perdido com o Salazarismo como também houve modificações profundas nos modos de relacionamento comunitário, como intensa mobilidade por motivos econômicos. Isso, em termos de repertório simbólico, significou a perda de lugares de memória, o não reconhecimento espacial, a opressão da técnica e do tecnológico interrompendo transações efetivas. Já um poeta maior do oitocentismo português, Cesário Verde, notara o aprisionamento do homem na cidade, sua Lisboa oitocentista, em transformação capitalista: "[...] Semelham-se a gaiolas, com viveiros, / as edificações somente emadeiradas; // [...] Triste cidade! Eu temo que me avives / Uma paixão defunta! // [...] Mas se vivemos, os emparedados, / sem árvores, no vale escuro das muralhas! [...]" (VERDE, poema O Sentimento dum Ocidental, 1992). No entanto, 
serão especialmente os poetas que começam a publicar nos anos setenta do século XX que vão dizer mais ostensivamente que Cesário estava certo.

Vale lembrar aqui um poeta e crítico como Joaquim Manuel Magalhães, autor de poemas instigantes para essa perspectiva, e voz com a qual poetas mais jovens dialogam diretamente. Suas páginas críticas, publicadas nos anos 80 e 90, bem refletiram sobre a rarefação mental e cultural no espaço português. Em um dos seus mais citados livros de ensaios críticos - Os dois crepúsculos (1981) -, o crítico manifesta-se não só sobre a poesia de alguns de seus contemporâneos como também sobre a sociedade de que é participante. Entre as crônicas sobre isso, destacamos uma intitulada "Sobre praias", em que o autor ataca veementemente o comportamento consumista e massificado de uma população que transforma a paisagem da praia num cenário sem ordem, sem educação e sem respeito humano e ecológico. Essa população "embrutecida“ produz sem limites lixo e é inconsciente de sua degradação cultural e existencial.

O que estou é a dar voz ao pavor, talvez pessoal, sem dúvida aumentado pela mediocridade das situações, de nelas assistir à massificação dos desejos.[...] É isto a sociedade de massas: promover que todos queiram a mesma coisa, até ao ponto de todos exigim de si que queiram a mesma coisa que todos. Quer se planifique o desejo, quer se faça dele mais-valia, vai tudo dar ao mesmo montão de gente que, neste caso, está à beira-mar (MAGALHÃES, 1981, p. 313-315).

Note-se o olhar do sujeito sobre o espaço degradado em que se encontra e o seu mal-estar frente a um mundo que rejeita e que despreza a poesia, a beleza, ou em outros termos o contato humano, a dignidade de ser. $\mathrm{O}$ espaço à sua volta está desfigurado e o poema se ergue desse chão de estrume e de restos como canto de oposição à força brutal do consumismo e à indiferença de um espaço urbano degradado, como procurei discutir em outro momento. Veja-se também, de sua autoria, o poema

\section{PÁRAMO}

Na varanda sem paz eu vejo o mar mas já não vejo junto desses olhos que viam o mar amordaçar-me. A varanda, todavia, ainda traz na ondulação, nas maresias a ilusão de um silêncio 
em que tu pretendias: aqui, nesta lei tão dura, senti que nada mais terei do que ser de ti. A varanda continua a sua conjura, eu continuo o desgaste do mar só que noutra jura a tua vida dura e até o mar te deixou de esperar.

O vário vento que vem e que voa sobre argolas com vasos de gerânios que tombam vagarosos e rosas sobre ruas ruidosas de Lisboa toca ao de leve no copo por que bebo esquecido e sozinho ali onde dantes vinhas com o maior apego ouvir ao fim da tarde eu olhar para ti.

Ao alto dessas ruas que Lisboa já não tem havia um andar quase arruinado com o estilhaço, a cólera, o fermento de quem se resignava também a que não valesse a pena nada. No vagar desse desmoronamento essa ruína foi tua e foi minha, o seu reboco de cal, a pele refém, a cisterna petrificada.

Amávamo-nos entre eléctricos que passavam do nascer do dia até ao nascer do dia.

Não há nada que se peça que nos seja dado mesmo quando gritamos alto por perdão. Merecemos tudo o que ficou fragmentado no pensamento que não sabe inebriar-se quando os sentidos perderam o condão.

Essas ruas de Lisboa que findaram como findaram os dedos que prenderam o bordão de ternura que tantos outros nos cortaram.

Tal qual o prédio caímos e apenas o pó desenha entre o que nem persigo um resto que sabe que está só porque nenhuma solidão vem ter consigo.

MAGALHÃES, Joaquim Manuel. Alta noite em alta fraga (2001)

Trata-se assim de falar de uma condição urbana difícil de suportar, vivida cotidianamente como um peso, uma violência interior. Se em metrópoles como São 
Paulo e Rio de Janeiro ${ }^{5}$, a violência se caracteriza de forma mais evidente com efeitos realmente criminosos, na poética portuguesa esse mal-estar é de outra fonte: interna e emocional, nomeando na linguagem poética a sensação de precariedade, de atravessamento físico pela velocidade de tudo (meios de transporte, telas, meios de comunicação e afins), afastando cada vez mais os sujeitos de seus afetos e de suas certezas, separando-os de uma memória afetiva ligada a pequenos territórios de emoção (a infância, a família, os amigos), o que gera solidão, estranhamento e aprisionamento existencial.

Como já escrevi antes e peço licença para me repetir, a desfiguração da paisagem natural (e de um imaginário do locus amoenus) ou a configuração de uma paisagem urbana não acolhedora parece impor aos poetas contemporâneos o tom elegíaco condizente com as experiências de perda, de vazio e de morte simbólica, em termos sócio-culturais, de suas realidades citadinas. A retomada da elegia como forma renovada da poesia mais recente merece aprofundamento. As experiências do urbano na contemporaneidade e seu reflexo no texto poético nos leva a pensar como essa atmosfera de ruína, de estranhamento e de desencontro se torna matéria de um lirismo onde domina não a heroicidade moderna mas a forte humanidade do um sujeito lírico que não oculta sua fraqueza, sua banalidade diária, seus medos e precariedades. Como desenvolve Jean-Michel Maulpoix $(2000)^{6}$, trata-se de observar no lirismo do final do século XX a renovação da elegia e a impossibilidade da épica e da ode.

Em relação aos países africanos lusófonos, a questão da representação da paisagem tem que ser tratada com outras balizas, pois a relação do homem com o espaço é muito diversa da do homem europeu ou americano. Sobre isso, compreende-se como as literaturas desses países são melhor recebidas no Brasil do que o texto europeu, pois o leitor brasileiro, com fortes raízes africanas, com uma memória abafada da cultura indígena e um passado colonial, parece reconhecer nessa produção seu rosto,

\footnotetext{
${ }^{5}$ Sobre a narrativa e poesia brasileira contemporâneas, na perspectiva da vivência do espaço, ver SUSSEKIND, 2005.

6 Tandis que l'épopée raconte les hauts faits et que l'ode encense les vainqueurs, l'élégie médite sur l'action et sur le sorte de l'homme. Elle devient volontiers gnomique et sentencieuse. Elle correspond à un relatif désengagement du poète vis-à-vis de l'action: son intériorité filtre et décompose les éléments objectifs du monde qui sont données à observer plus qu'à louer ou transformer. L'élégie est introspective. On y observe une dégraditon fatale de l'élément épique, en même temps qu'un effort pour en dégager le sens. L'élégie accomplit ainsi un glissment de l'épique vers le lyrique. [...] Travail de deuil et de mémoire, toute élégie formule un deuil qui doit être dépassé. (MAULPOIX, 2000, p. 193-194).
} 
para discutir os dilemas de sociedades colonizadas, formadas pela mestiçagem de culturas.

Descubro que a minha pele
já pouco guarda
das manhãs festivas.
Podia reter a brisa dos augúrios
as palavras que o medo despojou
até arder no germe dos murmúrios.
Escolher uma paisagem de silêncio
a súbita bravura do seu eco
a lâmina do frio que levanta.
Há tardes em que a chuva se interrompe
para que a sombra invoque outro temor:
só um silêncio assim podia revelar
razões guardadas de uma voz futura.

Tranquilas são as paisagens onde a idade não conta.

Eu falo do olhar crepuscular das feras

da noite e da gordura que segrega

a sua fidelíssima paciência

a cativar o cheiro de manadas quentes.

E da indiferença das grutas

poupadas ao esforço do labor do dia.

Ou de mulheres sentadas

rezando acordos entre o gesto e o fogo.

Espírito do lago

Espírito do fogo

a labareda e a margem não dizem mais que o encontro. (CARVALHO, 1988, 20).

\section{4. À GUISA DE CONCLUSÃO}

Enfim, o quadro é por demais vasto, complexo e nenhuma síntese é pertinente. Os estudos de paisagem e literatura sob nova perspectiva estão apenas começando entre nós, se compararmos com certa produção estrangeira, e, por isso, é fundamental o diálogo e a integração entre áreas como a Geografia e Letras. Por isso, acreditamos também que se torna cada vez mais necessária a efetivação de um grande plano de trabalho conjunto para constituir concretamente uma Geografia Literária, como área de 
conhecimento, tanto no seu aspecto diacrônico como sincrônico, permitindo que o estudo de paisagem deixe de ser um interesse pontual, a partir de um olhar interno de uma disciplina, para atingir o estatuto de uma nova área de investigação que, com metodologia definida e sistematização de conceitos oriundos de uma teorização da percepção, de mais ampla reflexão histórico-filosófica, de uma perspectiva cultural e linguística mais dialogante, discutirá grafias do mundo, grafias do literário, em torno de um operador específico: a paisagem, para saber formular questões interdisciplinares próprias a uma contemporaneidade de mundialização e de contínuos deslocamentos físicos e mentais, movimentos espaciais que se revelam também e muito no texto literário, essa outra espécie de geo-grafia.

\section{REFERÊNCIAS}

AUGÉ, Marc. Não-lugares, introdução a uma antropologia da supermodernidade. 6. ed. São Paulo: Papirus, 2007.

BERQUE, Augustin. Cinq propositions pour une théorie du paysage. Seyssel: Editions Champ Vallon, 1994.

CARLOS, Ana Fani Alessandri. Espaço-tempo na metrópole. São Paulo: Contexto, 2001.

CARVALHO, Ruy Duarte de. Hábito da terra. Poesia. Porto: Edições ASA, 1988. p. 20

COLLOT, Michel et al. (dir.). Paysage et poésie du romantisme à nos jours. Paris: José Corti, 2005.

. La notion de paysage dans la critique thématique. In: (dir.). Les enjeux du paysage. Bruxelles: Ousia, 1997.

. La poésie moderne et la structure d'horizon. Paris: PUF, 1989.

. L'horizon fabuleux I (XIX siècle) et II (XX siècle). Paris: José Corti, 1988.

MAGALHÃES, Joaquim Manuel. Os dois crepúsculos - sobre poesia portuguesa actual e outras crónicas. Lisboa: A Regra do Jogo, 1981.

MAULPOIX, Jean-Michel. Du lyrisme. 3.ed. Paris: José Corti, 2000.

ROGER, Alain. La théorie du paysage en France 1974-1994. Syssel: Champ Vallon, 1995. 
Ida Alves

SANSOT, Pierre. Poétique de la ville. Paris: Méridiens Klincksick, 1988.

SCHAMA, Simon. Paisagem e memória. São Paulo: Cia das Letras, 1995.

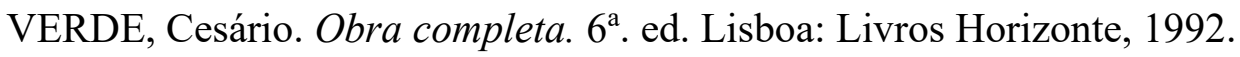

VIRILIO, Paul. Espaço crítico. Rio de Janeiro: Editora 34, 1993.

Recebido em 05/08/2018.

Aceito em 28/10/2018.

Publicado em 10/09/2020. 